\title{
Existe Espaço para a Sobrevivência do Mercosul?
}

Paulo Borba Casella ${ }^{1}$

Atendendo ao convite feito pela Coordenadora, Profa. Dra. Claudia Lima MARQUES, gostaria de compartilhar, com os alunos e leitores da Revista da Pós-Graduação da U.F.R.S., algumas idéias a respeito da formação do bloco econômico do MERCOSUL e da possível convivência deste com os blocos econômicos europeu e possível novo bloco no contexto interamericano, indagando se e em que medida se poderá esperar a convivência pacífica entre estes, preparando o caminho para a consolidação ou desaprecimento do MERCOSUL, em função do desafio da longa e complexa negociação que deverá seguir-se, até o final de 2005 e adiante, rumo à consolidação da ALCA, a Área de Livre Comércio das Américas. Logicamente, trata-se de fazer análise dos dados conhecidos e tentar situar o contexto do que poderá vir a formar-se no contexto da região.

Blocos regionais não são novidade no contexto interamericano e vários modelos e tamanhos vem sendo experimentados, com resultados substancialmente diversos, quanto à extensão da implementação e resultados alcançados. A existência do MERCOSUL e a continuidade deste estão entre as questões que terão de ser respondidas em futuro próximo. As recentes atitudes tomadas pelo governo da República Argentina,

${ }^{1}$ professor de direito internacional e direito da integração (USP); doutor e livredocente em direito internacional (USP), sócio de CASELLA ADVOGADOS, pcasella@casellaadv.com.br, tem .22 livros publicados, esp. coord. Quem tem medo da ALCA? (prefácio João Grandino RODAS, no prelo, 2004). 
na já chamada "guerra da geladeira" são muito pouco alvissareiras

Como professor universitário posso me permitir dizer o que penso, tendo compromisso com a verdade e com a minha consciência. Minhas opiniões pessoais podem permanecer pessoais, exceto na medida em que possam ser relevantes para situarmos a discussão e úteis para situar o estado atual e desdobramentos possiveis do fenômeno.

Nesse sentido, gostaria de situar em sucintas linhas os tópicos seguintes: o contexto internacional e a transformção da Europa integrada, o MERCOSUL, o NAFTA, e como pode ser e ficar a ALCA, para poder chegar à avaliação das perspectivas de sobrevivência $\mathrm{e}$ futuro possivel do MERCOSUL.

\section{contexto internacional e a transformação da Europa integrada}

No contexto internacional presente, parecemos estar padecendo de miopia exacerbada, enxergando somente nosso próprio umbigo e alguns pontos isolados do planeta, parecendo nos esquecer, como já dizia SHAKESPEARE, que há muito mais coisas entre o céu e a terra que supõe a nossa vã filosofia. Além do quintal de nossa casa, muitas coisas estão ocorrendo, e merecem que se preste atenção:

- mergulhados nas conjunturas e falcatruas da política intema brasileira, tão ocupados e preocupados com pequenos estragos do dia-a-dia, depois de permanecermos durante anos como a "oitava economia do mundo", fomos rebaixados, desde o início do ano de 2004, pelos Países Baixos, descendo da $14^{\mathrm{a}}$ para a $15^{\mathrm{a}}$ economia mundial - muito embora tenha a Holanda 16 milhões de habitantes (menos de um décimo da população brasileira) em território de 41.500 quilômetros quadrados; 
- ufanamo-nos em ver aumentar o volume das exportações brasileiras e parecemos nos esquecer de que estas estão aumentando em termos absolutos sim, como volume exportado, mas decrescentes em termos relativos, tendo aumentado menos rápido do que o comércio mundial, do qual o Brasil já manteve durante anos algo entre 1.5 a $2 \%$ do total e hoje mal nos equilibramos em $1 \%$ - ou seja, sequer estamos mantendo nosso papel como "global trader" relevante;

- em nome de fortalecimento de laços comerciais, em recente viagem presidencial à República Popular da China, o governo brasileiro tomou posições desastrosas em relação ao direito internacional, e aceitou acatar muito mais do que poderá receber em troca: reconhecer a China como economia de mercado (?), aceitar a retomada de Taiwan (??), reconhecer a ocupação e desaparecimento do Tibete (???) - retribuindo os gestos feitos pelo Brasil, a China como "presente" rejeitou vários embarques de soja, alegando razões de não conformidade com especificações contratadas, enquanto operadores do setor diziam terem sido estes embarques feitos corretamente mas que provavelmente desejariam nossos compradores de soja chineses pressionar os exportadores brasileiros que tinham feito as vendas com as cotações do produto em alta no mercado internacional, e as entregas estariam ocorrendo no momento em que estas mesmas cotações estão em baixa;

- ocupam tempo e espaço desmesurados os desmandos do partido ora governante em Israel em relação aos palestino ${ }^{2}$ e os estragos da ocupação do presente governo norte-americano no Iraque ${ }^{3}$,

\footnotetext{
2 Não sou nem pretendo me tornar, não aceito ser apontado como "anti-semita", mas não posso aceitar as violações do direito internacional pelo partido governando atualmente o estado de Israel.

${ }^{3}$ Não posso nem pretendo aceitar como válidas as esfarrapadas desculpas para a ocupação de estado, que era soberano e independente, cujas alegadas armas de destruição em massa não foram até aqui encontradas, ademais era estado laico na região, ora correndo o risco de tornar-se fundamentalista, e que até aqui não tinha vinculação com a AL QUAEDA. Tudo isso mudou e ainda pode se tornar pior, em razão da ocupação militar norte-americana, que está se tornando desastrosa.
} 
esquecendo-nos de quanta coisa relevante e diferente está acontecendo no mundo, neste momento: a Europa se transforma, em escala inusitada, e poderá afetar não somente o seu futuro funcionamento interno como também as suas prioridades externas, inclusive no relacionamento com o Brasil, com o MERCOSUL e na configuração do Acordo MERCOSUL-UE, em negociação há dez anos, praticamente desde a celebração do Acordo-quadro entre U.E. e MERCOSUL, assinado em Madri, em 15 de dezembro de 1995.

\section{a Europa se transforma, em escala inusitada}

Desde $1^{\circ}$ de maio de 2004, dez novos Estados ingressaram na União Européia (UE): encetando a quinta ampliação deste espaço econômico regional, a mais abrangente e mais espetacular, das até hoje encetadas, em espaço economicamente integrado que passou a somar 25 países, além de outros, como Romênia e Bulgária, que estão à espera, aguardando a oportunidade para $2007^{4}$.

Europa sem fronteiras, em tal extensão, nunca existiu. Enormes desafios econômico, político, operacional e institucional, para funcionar a UE. Desafio econômico e político: tornar eficaz o conjunto desse mercado único, em progressiva união econômica e monetária. A absorção dos dez Estados exige esforço à escala da transformação, para o mesmo patamar de renda per capita e eficiência econômica.

Externamente, tratar-se de manter grau mínimo de projeção externa de unidade interna, em boa medida ainda em construção: UE pode mudar o presente desequilibrio de forças como elemento

${ }^{4}$ A respeito, i.a., v. P. B. CASELLA "Ampliação da União Européia: a Europa central se integra" em Claudia Lima MARQUES e Nadia de ARAUJO (coords.) ... (Rio, Renovar, 2005), bem como, v. tb., a respeito: "Dez novos Estados na U.E." (Gazeta Mercantil, 7 de maio de 2004, p. A-3), bem como União Européia: instituições e ordenamento jurídico (São Paulo, LTr Ed., $2^{a}$ ed., 2002). 
crucial na ordem internacional: política externa comum da UE, acordos com Rússia, Japão, Índia, China, Brasil e MERCOSUL estes podem ser dados saudáveis e construir nova co-relação internacional de forças, para o futuro do planeta.

Céticos enxergam defeitos e problemas - estes não serão pequenos - esta etapa da integração transforma o mapa político da Europa, o conteúdo econômico e social interno e marca o futuro da integração regional. Reflexos externos da ampliação: informação sobre esses Estados e avaliar o impacto das adesões, na UE e terceiros Estados, inclusive Brasil e MERCOSUL: acarreta mudança nos investimentos e pautas de importação/exportação do principal parceiro comercial e investidor.

Oportuno e necessário continuar e concluir a negociação de acordo comercial entre UE e MERCOSUL, para assegurar acesso a esse enorme mercado integrado no futuro.

A Europa integrada, superados os desafios internos e operacionais tremendos que terão de ser enfrentados, não será somente gigante econômico e anão pouco ágil nas relações internacionais: ainda está por desenhar-se o mapa da Europa integrada nas suas repercussões no mundo extra-europeu. Ainda está para ser escrito esse capítulo. Vamos conhecer mais a respeito, nos próximos dez a vinte e cinco anos. Será interessante observar.

\section{MERCOSUL}

Acreditei e continuo acreditando no projeto de integração regional. A necessidade e importância estratégica deste Mercado Comum do Sul, não sornente como mercado, mas como interlocutor nas relações internacionais, para os países da região se fazerem presentes e serem ouvidos em contexto internacional mais amplo 
podem e devem ser enfatizadas. O projeto em si é válido e continua sendo necessário. A forma como foi implementado e como vem sendo conduzido deixam a desejar e estão dandos os frutos pelo que se plantou desde o início: o modelo estritamente intergovernamental e institucionalmente frágil que foi adotado, por razões politicas, para manter as alegadas "flexibilidade" e "gradualidade" estão agora sendo responsáveis pelo estado atual do processo de integração, que vive o impasse político mais grave, desde que foi encetado.

Minhas credenciais MERCOSUL contam doze anos de trabalho relacionados ao tema da integração regional, lecionando a matéria na USP, todos os anos, desde 1993, tendo lecionado a respeito em diversas universidades ${ }^{5}$, na Europa e nas Américas, bem como, além de participações em diversas obras coletivas, congressos e seminários, publicado alguns livros ${ }^{6}$, a respeito do tema. Em suma, não datam da última hora, nem foram improvisadas em semanas.

${ }^{5}$ Conferências em Universidades brasileiras e do exterior, inciuindo: Amsterdam (1997, 2000), Asunción (1996, 1997), Buenos Aires (1997), Coimbra (1996, 1999), Córdoba (1999), Düsseldorf (1995), Hamburg (1993, 1995), Heidelberg (1991, 1993, 1995, 1997), Helsinki (1996), Lodz, Lyon (1999), Milão (1995), Montevidéu (1996, 1997), Nice (1995, 1996), Ottawa (1997), Paris (1996), Rennes (1996), Saarbrücken (1993, 1995), Tóquio (1995), Tübingen (1995).

' São estes: MERCOSUL: integração regional e globalização (coord. P. B. CASELLA et al.; Rio, Renovar, 2000), Guerra comercial ou integração mundial pelo comércio? - a OMC e o Brasil (coord. P. B. CASELLA e A. A. MERCADANTE; S. Paulo, LTr, 1998), Integração jurídica interamericana (coord. P. B. CASELLA e N. ARAUJO; pref. G. E. do NASCIMENTO E SILVA; S. Paulo, LTr, 1998), Instituições do MERCOSUL (Brasília, Estudos da Integração, 1997), MERCOSUL, exigências e perspectivas: integração e consolidação de espaço econômico (pref. Celso D. de A. MELLO, São Paulo, LTr Ed., 1996), Contratos internacionais e direito econômico no MERCOSUL: após o término do período de transição (coord. P. B. CASELLA; pref. J. DOLINGER; S. Paulo, $\mathrm{LTr}_{r}$ 1996), Direito e comércio internacional: tendências e perspectivas (coord. P. B. CASELLA, L.BAPTISTA \& H. HUCK; S. Paulo, LTr, 1994), MERCOSUL: das negociações à implantação (coord. P. B. CASELLA, L. BAPTISTA \& A. A. MERCADANTE; pref. C. LAFER; S. Paulo, LTr, 1994; $2^{\mathrm{a}}$ ed., 1998), Comparative approach to competition law in the E.C. and the MERCOSUL (Saarbrücken, Europa-Institut, vol. 301, 1993). 
Em avaliação de conjunto, pois ninguém pode ser obrigado a ouvir mais uma vez resumo histórico da evolução do MERCOSUL, desde a assinatura do Tratado de Assunção, de 26 de março de 1991, até o término do segundo quinqüênio de implementação da TEC, que deverá ter lugar em 31 de dezembro de 2005.

Até a data de 31 de dezembro de 2005 deverá estar definido se e em que medida o MERCOSUL poderá se tornar um mercado comum. Teremos de ver se 31 de dezembro de 2005 se o MERCOSUL sobreviverá à negociação da ALCA e como estará depois de passar por isso.

\section{NAFTA}

A Associação norte-americana de livre comércio, ou North American Free Trade Agreement (NAFTA), foi celebrada entre Canadá, Estados Unidos e México, em Washington, em 8 e 17 de dezembro de 1992, em Ottawa, em 11 e 17 de dezembro, e na cidade do México, em 14 e 17 de dezembro de 1992 , tendo entrado em vigor em $1^{2}$ de janeiro de 19947, consistindo no mais abrangente acordo comercial — sem pretender colocar-se como mercado comum - e a primeira zona de livre comércio bilateral negociada entre parceiros comerciais, dois quais dois países desenvolvidos e um país em vias de desenvolvimento.

Consiste o NAFTA, basicamente, em versão ampliada e aperfeiçoada do Acordo de Livre Comércio, assinado em 2 de janeiro de 1988, entre Estados Unidos e Canadá, representando o coroamento bem sucedido de esforços feitos durante o último século, no sentido de alcançar algum tipo de acordo comercial entre os dois países ${ }^{8}$. Em

\footnotetext{
7 North American Free Trade Agreement, entre Canadá, Estados Unidos e México, em Washington, em 8 e 17 de dezembro de 1992, em Ottawa, em 11 e 17 de dezembro e na cidade do México, em 14 e 17 de dezembro de 1992 (texto reproduzido em ILM 32.1993, pp. 289/456 e 605/799).

8 United States-Canada Free Trade Agreement (texto reproduzido in Basic Documents of International Economic Law, 1990, t. II, pp. 353/524; com nota introdutória de Judith Hippler BELLO).
} 
ampla medida, o NAFTA cria para o México a obrigação de implementar o grau de liberalização comercial e de investimentos equivalente ao anteriormente estipulado entre Estados Unidos e Canadá, nos termos do Acordo de 1988, ao mesmo tempo em que amplia o escopo desse acordo anterior, incluindo a proteção de direitos de propriedade intelectual, normas visando evitar distorções em matéria de investimentos e cobrindo também a prestação de serviços de transporte. Representou o NAFTA substancial mudança da política externa mexicana, trocando décadas de nacionalismo e autarcia econômica, confirmando seu recente compromisso com a economia de mercado.

O Acordo estipula significativos compromissos em matéria de liberalização de comércio e investimentos, comportando a eliminação progressiva de barreiras tarifárias e da maioria das barreiras não-tarifárias ao comércio regional, em período de dez anos, com exceção de alguns setores (com regime de exceção no caso dos assim chamados import sensitive products), para os quais foi estipulado período de quinze anos. Ocorrerão desenvolvimentos concomitantes entre os três parceiros, na medida em que no comércio bilateral entre Estados Unidos e Canadá a eliminação progressiva de tarifas prossegue conforme cronograma estipulado no Acordo de 1988. O sistema de solução de controvérsias previsto no Acordo de 1988 foi estendido ao México, enquanto este se obrigou a remodelar procedimentos administrativos, conferindo-lhes maior transparência, bem como alinhar seus procedimentos legais, em matéria de normas anti-dumping e outros, pelos modelos canadense e norte-americano.

As principais áreas de liberalização de comércio e investimento abrangidas pelo NAFTA compreendem:

- produtos agrícolas terão livre comércio entre Estados Unidos e México em período de quinze anos, fazendo a imediata conversão das principais barreiras comerciais preexistentes em patamares tarifários, estipulando período máximo de quinze anos para a eliminação de tarifas acima das quotas; 
- em matéria de investimentos e mecanismos de solução de controvérsias fica estipulado o tratamento nacional para investidores do NAFTA, removendo a maioria das exigências de desempenho (performance requirements) sobre investimentos na região, abrindo novas perspectivas de investimento em setores-chaves da economia mexicana, tais como produtos petroquímicos e serviços financeiros;

- o NAFTA coloca parâmetro para futuras negociações regionais e multilaterais, abrindo substancialmente o mercado mexicano de serviços financeiros a participantes dos Estados Unidos e Canadá, até o ano 2000 , e removendo obstáculos essenciais em matéria de transporte terrestre e serviços de telecomunicação.

O NAFTA assenta as bases nas quais poderão vir a se agregar outros países a esse esforço, aplicando os conceitos de "união aduaneira" e "zona de livre comércio" do artigo XXIV do GATT, do qual retoma numerosos dispositivos, baseado no "tratamento nacional" $\mathrm{e}$ fórmula limitada da "cláusula de nação mais favorecida", mas claramente a integração de mercados deverá ser construída a partir de modelo de cooperação intergovernamental, não ocorrendo elementos supranacionais, conforme modelo europeu ${ }^{10}$.

Pelo peso específico dos participantes, conferindo-lhe sua vis attractiva, desde o início do processo se poderia imaginar essa zona de livre comércio norte-americana ampliando-se, nos próximos dez ou quinze anos, até atingir escala continental, como provavelmente virá a ser a ALCA, mas atuando a partir de bases

\footnotetext{
${ }^{9}$ Acordo Geral de Tarifas e Comércio cfr. Guide to GATT Law and Practice: analytical index (GATT, Genebra, 6a ed, 1994), art. XXIV: "territorial application frontier traffic _customs unions and free trade areas" (pp. 735/808), contendo dispositivos aplicáveis em relação a uniões aduaneiras e zonas de livre comércio; art. I: "general most-favoured-nation treatment" (pp. 23/60); Canadá-MéxicoUnited States: North American Free Trade Agreement (in I.L.M. 32.1993, pp. 289 s5. art. 101).

10 Jean-Yves GRENON, "L'accord de libre échange nord-américain, comparé à la Communauté économique européenne" (R.M.C., 36.1993, n. 367, abr., p.p. 306/ 320).
} 
mais detalhadas e realistas que confiram efetiva operacionalidade à empreitada.

Não cabe, aqui, descer a análise setorial pormenorizada de áreas e setores abrangidos pelo NAFTA, valendo destacar a premissa fundamental e conceitos de alcance geral, onde se coloca expressamente a compatibilidade dos termos do Acordo com as normas do artigo XXIV do GATT-OMC, em relação a uniões aduaneiras e zonas de livre comércio, com previsão de precedência dos termos do NAFTA entre as Partes-contratantes, em relação a outros acordos, ressalvadas as obrigações decorrentes do GATTOMC, conforme estipulam os artigos 101 e 103, e os objetivos do NAFTA, relacionados no artigo 102:

- eliminar barreiras comerciais e facilitar o comércio de bens e serviços entre os territórios dos Estados-membros;

- promover condições de lealdade da concorrência na zona de livre comércio;

- incrementar substancialmente as oportunidades de investimento nos territórios dos Estados-membros;

- promover adequada e efetiva proteção e cumprimento de direitos de propriedade intelectual no território de cada Estadomembro;

- criar procedimentos efetivos para a implementação e aplicação deste Acordo, para sua administração conjunta, bem como para a solução de controvérsias; e

- estabelecer o quadro institucional para a cooperação trilateral, regional e multilateral para expandir e ampliar os benefícios do NAFTA.

Fica estipulado, outrossim, que a interpretação e aplicação dos objetivos do Acordo NAFTA será feita nos termos de seus objetivos e em conformidade com as normas aplicáveis de direito internacional. 
Deve-se frisar a consistência entre os meios e fins, onde se propõe alcançar zona de livre comércio, dotando o Acordo dos meios necessários para a consecução de seus objetivos, além da ênfase na eliminação de barreiras ao comércio de bens e serviços no território dos Estados-membros, inerente ao conceito de "zona de livre comércio", também em áreas vitais tais como a lealdade da concorrência na zona de livre comércio, o incremento e a proteção ao investimento, a proteção de direitos de propriedade intelectual, o estabelecimento de mecanismos visando a solução de controvérsias e implementação e aplicação do Acordo, bem como do quadro institucional para expandir e ampliar a cooperação trilateral, regional e multilateral, em consonância com o Acordo.

O Acordo NAFTA, dividido em oito partes e vinte e dois capítulos, além de vários anexos técnicos(43), regula, sucessivamente, na parte primeira, normas gerais e definições; na parte segunda, o comércio de mercadorias, contendo previsões relativas ao tratamento nacional e acesso a mercados (cap. iii), normas de origem (cap. iv) e procedimentos aduaneiros (cap. v), energia e produtos petroquímicos básicos (cap. vi), agricultura e medidas sanitárias e fito-sanitárias (cap. vii), bem como ações de caráter emergencial; na parte terceira, as barreiras técnicas ao comércio; na parte quarta, licitações públicas; na parte quinta, investimentos, serviços e assuntos conexos, com destaque para o comércio de serviços além-fronteiras (cap. xii), telecomunicações (cap. xiii) e serviços financeiros (cap. xiv), política de concorrência, e regime aplicável aos monopólios e empresas estatais (cap. XV) e a residência temporária para fins de negócios (cap. xvi); a parte sexta regula matérias relativas à propriedade intelectual; a parte sétima contém as normas relativas a matérias administrativas e institucionais, destacando a publicação, notificação e administração de normas (cap. xviii), a revisão e mecanismos de solução de controvérsias em matérias de anti-dumping e direitos compensatórios (cap. xix), provisões institucionais e mecanismos de solução de controvérsias (cap. xx); enquanto a oitava e última 


\section{8}

parte contém disposîções diversas, elencando as exceções (cap. xxi) e disposições finais (cap. xxii). A meritória extensão da regulamentação aborda áreas fundamentais da vida econômica dos Estados, onde a atuação destes, em contexto de zona de livre comércio, exige mínimo de coordenação indispensável, sem a qual a implementação da proposta ficaria inviabilizada.

As instituições previstas pelo Acordo NAFTA são a Comissão de Livre-comércio e o Secretariado, assessorados por Comitês e grupos de trabalho. llustrativos de pragmatismo responsável são os dispositivos especificos com relação à remuneração e reembolso de despesas, que poderiam ser negligenciados como aspectos menores, mas evidenciam a seriedade do compromisso assumido e a relação direta entre as iniciativas de cada Estado Parte e os custos dai decorrentes.

As atribuições da Comissão de Livre-comércio, integrada por representantes de nivel ministerial ou substitutos, são estipuladas pelo artigo 2001, abrangendo a supervisão da implementação do Acordo bem como a continuidade de sua elaboração, a solução de controvérsias oriundas de sua interpretação ou aplicação, a supervisão da atividade dos Comitês e grupos de trabalho, bem como quaisquer outras matérias atinentes à operação do Acordo, podendo, para tanto: estipular e delegar responsabilidades para comitês, grupos de trabalho e grupos de experts; consultar pessoas ou entidades nãogovernamentais, bem como tomar quaisquer outras medidas, no exercício de suas funções, conforme seja acordado pelas Partes. Cabe à Comissão estipular suas normas internas e procedimentos, devendo todas as decisões ser tomadas por consenso, exceto na medida em que seja diversamente estipulado pela Comissão, realizando reuniões anuais, presididas sucessivamente pelos Estados contratantes. 
O Secretariado, nos termos do artigo 2002, estabelecido e supervisionado pela Comissão, será integrado por secções nacionais, cabendo a cada Estado estabelecer escritório permanente para sua Secção, sendo responsável pela operação e despesas desta, bem como pela remuneração de especialistas e integrantes dos comitês e conselhos científicos, estabelecidos nos termos do Anexo 2002.2, designando indivíduo para atuar como Secretário de sua Secção nacional, que será responsável por sua administração e direção, bem como notificando à Comissão a localização de sua Secção nacional. Compete ao Secretariado: dar apoio à Comissão bem como prestar assistência administrativa a painéis e comitês constituídos, nos termos do cap. xix do Acordo, para a revisão e mecanismos de solução de controvérsias em matéria de medidas anti-dumping e direitos compensatórios, conforme procedimentos estipulados no artigo 1908 do Acordo, bem como painéis constituídos nos termos dos procedimentos gerais de solução de controvérsias, conforme regulado pelos artigos 2011 e 2012 do Acordo.

Em matéria de solução de controvérsias coloca-se a flexibilidade e multiplicidade de mecanismos possiveis para atuação, compreendendo: cooperação, o recurso aos mecanismos de solução de controvérsia em sentido estrito, os mecanismos de solução de controvérsias do GATT, os bons ofícios, a conciliação, a mediação, a arbitragem, bem como procedimentos nacionais, tanto judiciais como administrativos.

Além do peso específico do NAFTA, como agente do comércio internacional, reflete este agrupamento econômico a tendência mundial à consolidação de blocos e a ênfase crescente dispensada aos assuntos econômicos, no contexto internacional posterior ao fim da guerra fria, marcando a necessidade de reorientação de políticas externas nacionais, colocadas em coordenação com outros Estados, em vista da consecução de objetivos comuns, estabelecidos por tratados e acordos, quer 
formais como informais, mesmo sem acarretar a criação de estruturas institucionais supranacionais, na medida em que se coloquem diferentes Estados como parceiros econômicos.

Superada a ideologização das relações internacionais que marcou as quatro décadas da guerra fria, de 1949-1989, estabelecem-se, a partir do fim desta fase, as prioridades econômicas e a necessidade de adequação dos instrumentos políticos ao mais conveniente desempenho de tais finalidades. $O$ pragmatismo, contudo, não é neutro. O modelo está sendo trazido, diretamente da experiência da NAFTA para a escala continental mais abrangente possível, sob o formato ALCA. Será viável pretender tal transposição, sem substanciais ajustes conceituais e no tocante aos objetivos? Esta resposta teremos dentro de menos de ano e meio.

\section{ALCA}

A Área de Livre Comércio das Américas é um projeto de longa data. Os esforços de integração interamericana, tenham estes sido encetados quer em escala continental como regional, nunca chegaram a alcançar a indispensável combinação de flexibilidade e resistência institucional, com o conseqüente registro de integração substantiva nas áreas relevantes para a consecução dos projetos de integração, bem como a ampliação da integração para áreas anteriormente não contempladas.

Na sua formatação atual, tem recebido enormes reações de hostilidade, em razão da forma nefasta e arrogante pela qual este proposta vem sendo encaminhada pelos representantes do governo dos Estados Unidos, especialmente na área comercial.

Este anseio, que permeia o continente, de longa data, mais e mais vem sendo percebido como projeto dos Estados Unidos e 
como tal encontrando saudável desconfiança por parte de muitos dentre os governos dos países da região, oscilando entre o fascínio e o terror, diante da desproporção do tamanho das economias e diferença de dinamismo destas e a necessidade, ao mesmo tempo, de salvaguardar-se sem contudo perder acesso a esse mercado que deve formar-se em futuro próximo, e deve alterar substancialmente os fluxos de livre comércio no espaço continental.

A implementação da ALCA poderá significar a operação de zona de livre comércio estendendo-se do Yukon até o extremo sul da Patagônia. Sem pretender configurar "mercado comum" ou estender-se institucionalmente até o ponto de criar estruturas comuns, poderá conter ALCA, não obstante a suposta extensão das exceções, muitas vezes apontada, os elementos necessários para operar com adequação substancial entre mecanismos adotados e fins pretendidos. Esta região integrada será, pelo próprio peso da economia norte-americana, somada ao Canadá e México, que separadamente tinham nos Estados Unidos, seu maior parceiro comercial em ambos os casos, somando-se as respectivas participações de.comércio (importação e exportação) de todos os demais países do continente em relação aos três integrantes da NAFTA e a escala crescente de comércio, em escala continental, decorrente da supressão das até aqui vigentes barreiras ao comércio. Esses elementos agregados apontam no sentido de que a ALCA deverá, inevitavelmente, como novo bloco econômico, tornar-se um dos principais agentes do comércio mundial.

Pela primeira vez, na história das Américas, estaria a totalidade dos países da região, exceto Cuba, agregada em única zona de livre comércio, incluindo: Antigua e Barbuda, Argentina, Commonwealth das Bahamas, Barbados, Belize, Bolívia, Brasil, Canadá, Chile, Colômbia, Costa Rica, Commonwealth de Dominica, Equador, El Salvador, Estados Unidos da América, Granada, Guatemala, República Cooperativa da Guiana, Haiti, Honduras, Jamaica, México, Nicarágua, Panamá, Paraguai, Peru, 
República Dominicana, Federação de San Kitts e Nevis, Santa Lúcia, São Vicente e Granadinas, Suriname, Trinidad y Tobago, Uruguai e Venezuela.

No estágio atual da negociação, encontra-se divulgada a terceira minuta de acordo preliminar, basicamente isolado o texto, entre colchetes, seguindo a lógica, segundo a qual nada estará decidido, até que tudo esteja decidido. O exame da minuta do acordo preliminar pode ser instrutivo para situar alguns conceitos básicos, em relação ao projeto de Área de Livre Comércio das Américas.

No capítulo dos assuntos institucionais a pauta está para ser definida.

Com relação ao propósito do acordo, prevê-se o estabelecimento de área de livre comércio, com fundamento no Artigo XXIV do Acordo Geral sobre Tarifas Aduaneiras e Comércio (GATT) de 1994 e Entendimento deste, bem como o Artigo $V$ do Acordo Geral sobre Comércio de Serviços (GATS). Nos termos da proposta de artigo IV, as Partes confirmam os direitos e obrigações vigentes entre estas, em conformidade com a OMC. Nos casos de incompatibilidade entre as disposições do Acordo da $\mathrm{OMC}$ e as disposições deste Acordo, estas últimas prevalecerão na medida da incompatibilidade.

\section{Os objetivos do Acordo são:}

[a) a liberalização do comércio a fim de gerar crescimento econômico e prosperidade, contribuindo para a expansão do comércio mundial;] [b) gerar níveis crescentes de comércio de [mercadorias][bens] e serviços, e de investimento, mediante a liberalização dos mercados, por meio de regras [justas claras, estáveis e previsiveis;] [justas, transparentes, previsíveis, coerentes e que não tenham efeito contraproducente ao livre comércio;]] [c) 
melhorar a concorrência e as condições de acesso ao mercado de bens e serviços entre as Partes, incluindo a área de compras do setor público;] [d) eliminar obstáculos, restrições e/ou distorções desnecessárias ao livre comércio entre as Partes, [inclusive práticas de comércio desleal, medidas para-tarifárias, restrições injustificadas, subsídios e apoio interno ao comércio de bens e serviços];] [e) eliminar as barreiras ao movimento de capitais e pessoas de negócios entre as Partes;] [f) propiciar o desenvolvimento de uma infra-estrutura hemisférica que facilite a circulação de bens, serviços e investimentos; e] [g) estabelecer mecanismos que garantam um maior acesso à tecnologia, mediante a cooperação econômica e a assistência técnica.]Os princípios que regem a ALCA são: [a) as regras acordadas deverão ser claras, transparentes e estáveis, para evitar a possibilidade de que qualquer Parte possa aplicar medidas unilaterais, arbitrárias e/ou discricionárias, em detrimento de uma ou várias das demais Partes;] [b) a transparência nas ações das Partes e dos órgãos estabelecidos neste Acordo;] [c) a congruência dos direitos e obrigações que emanem do presente Acordo com as regras e disciplinas da Organização Mundial do Comércio (OMC);] [d) a coexistência deste Acordo com acordos bilaterais e sub-regionais, na medida em que os direitos e obrigações decorrentes desses acordos tenham maior alcance que os deste Acordo;] [e) o tratamento especial e diferenciado, considerando as amplas diferenças nos níveis de desenvolvimento e tamanho das economias das Partes, para promover a plena participação das Partes;] [f) a adoção de decisões por consenso;] [g) a igualdade soberana das Partes;] [h) a boa fé no cumprimento dos compromissos assumidos pelas Partes no marco do Acordo.]

O projeto de integração continental na ALCA vem sofrendo oscilações, nos últimos tempos, entre a rejeição e a perspectiva favorável para avaliar a integração, como um todo, em relação ao conjunto das Américas. Mais que as razões passageiras do momento, cabe considerar o interesse e papel possivel do Brasil, 


\section{4}

no que chamaria a "perspectiva continental para a integração nas Américas".

Trata-se de procurar enxergar o processo de integração, como um todo, além dos condicionamentos resultantes dos quadros internos recentes, na perspectiva do conjunto das Américas, com crescente adoção, por estados democráticos de direito, da ênfase no livre mercado. Todos concordam com a idéia e todos têm as suas respectivas reservas (abertamente admitidas ou escusadamente defendidas) em relação à sua implementação.

Dados cruciais devem ser levados em conta: soube e precisa saber o Brasil fazer-se presente; soube e precisa saber o MERCOSUL manter-se unido, sobrevivendo como bloco e acordo regional, mesmo diante da pressão norte-americana. Soubemos e precisamos continuar sabendo colocar pauta mínima de trabalho: se aos Estados Unidos e Canadá, em resumo o NAFTA, interessa liberalizar o mercado continental para produtos manufaturados, ao Brasil e Argentina, em suma ao MERCOSUL, interessa igualmente ou ainda mais liberalizar o mercado para produtos agro-industriais.

A colocação dessa pauta de liberalização generalizada do livre comércio nas Américas não somente pode representar base realista para a construção do livre comércio nas Américas como dar parâmetro para futuras negociações, no âmbito da Organização Mundial do Comércio, tendentes à consolidação de patamares mais elevados de liberalização do comércio mundial, como pode ser reestruturação relevante do conjunto do comércio nas Américas. Mas o formato final da ALCA todavia não se acha definido e ainda exigirá enorme trabalho e empenho na negociação.

No Brasil deste momento, tendemos a ver somente as condicionantes internas, esquecendo-nos estar o país, e nós nele, em meio ao processo de consolidação de espaço econômico, em escala continental, pela primeira vez na história, negligenciando o 
legado impressionante como as extraordinárias realizações do processo de integração, nos últimos quinze anos.

As perspectivas para os próximos cinco ou dez anos são ainda mais atraentes, mas existem pressupostos para a implementação dessa inserção internacional em contexto globalizado, onde se coloca enorme descompasso entre a economia e o direito, face ao desafio da globalização, pois este, além do modismo terminológico, é fenômeno ainda escassamente conhecido e praticado no contexto jurídico: os ordenamentos nacionais, ainda são vistos e pensados sob perspectiva se não excessivamente, ao menos predominantemente nacional.

A diferença de enfoque e tratamento do direito e do comércio cria descompasso essencial entre as atividades econômicas e políticas dos Estados, separadamente considerados, enfrentando problemas que vão do controle do crime organizado, do terrorismo internacional, da poluição e conservação do meio ambiente, das telecomunicações e tantos outros campos, e a natureza intrinsecamente internacional dessas questões que desconhecem fronteiras entre os paises, e nos quais problemas internacionais exigem soluções internacional, multilateralmente negociadas e expressas em regras de direito internacional. Tais questões desconhecem fronteiras, e nenhum estado será capaz de as resolver unilateralmente: os políticos e os ordenamentos jurídicos nacionais, muitas vezes ainda estão agarrados aos territórios e idiossincrasias nacionais, parecendo esquecer-se de que o mundo é muito mais complexo e mais amplo.

Tudo isso tem de ser levado em conta, quando se pensa e se projeta qual deve e pode ser o conceito para operar o "direito nas Américas", nos próximos anos, pois até o final de 2005, deverá estar implementada a ALCA, a Área de Livre Comércio das Américas. Como vamos estar pensando e praticando o direito: terá sido reduzido o abismo operacional que ainda separa o comércio, 
praticado de modo crescentemente internacionalizado e o direito, ainda excessivamente apegado ao torrão de vigência territorial?

Assim pertinente e necessário afigura-se pensar e discutir o direito, nas Américas, para o próximo milênio, para fazer face aos desafios e exigências operacionais do mundo globalizado.

A simultanea rejeição interna e aceitação internacional do projeto ALCA é dado a se ter presente, pois países como o Chile e a Argentina vem se engajando firmemente em preparar terreno favorável à consolidação de área de livre comércio nas Américas. O Brasil vem oscilando entre a aceitação e a tendência à rejeição do projeto. Vale registrar nota de apreensão: considerado como projeto de integração continental, vem a ALCA despertando, de um lado crescente interesse e curiosidade, também à luz dos significativos resultados que podem ser alcançados, e de outro rejeição orquestrada inclusive em descabida "consulta popular" organizada por paróquias católicas. Deveriam igrejas antes aterse a questões de doutrina e fé, e não de organização econômica da sociedade.

Temos projeto nas mãos, com enorme responsabilidade para o Brasil, nesta altura e quadro, no qual precisamos ter a combinação adequada de maturidade e tranquilidade, para fazer as coisas avançarem bem. O Brasil soube marcar sua posição nacional e soube fazer ver o MERCOSUL como dados relevantes a serem computados no contexto de qualquer esforço rumo à implementação de área continental de livre comércio. Se saberemos ter essa sabedoria, na continuidade da implantação do projeto, ainda está para ser visto.

\section{poderá sobreviver o MERCOSUL ?}

Atribui-se a Porfírio DIAZ: "pobre México, tão longe de Deus e tão próximo dos Estados Unidos". Esta exclamação é uma realidade para todos os países do continente-mesmo alguns mais 
distantes, tais como Iraque e Afeganistão vem sentindo a "mão pesada" de "Tio Sam" nos últimos anos.

Chave para leitura da atitude norte-americana, em relação à América Latina, em geral, poderia ser caracterizada como a sindrome do irmão mais velho ("big brother"): a mania de achar que os irmãos mais novos precisarão sempre de conselho e de atitudes de certa crítica, como se fossem incapazes de se cuidar sozinhos, mesmo quando vão indo bastante bem, obrigado, inclusive em relação aos negócios da família, conseguindo fazer que herança comum, mais ou menos "encalhada", pudesse passar a ser utilmente eapitalizada, tanto para uso interno como nos reflexos internacionais desse projeto de integração, como o que se encontra em curso, no MERCOSUL.

Desse modo, a Área de Livre Comércio das Américas (ALCA), que poderia ser algo que viesse acoplar-se aos dois pólos regionais já em andamento no Continente: a Área de Livre Comércio da América do Norte (NAFTA) e o MERCOSUL, passando a congregar todos os países do hemisfério - até quando sem Cuba, alguém pode esclarecer? - em acordo comercial de interesse e utilidade possivel para todos. Contudo, não está em discussão a ALCA em si, que pode ser útil ou não - inclusive para o Brasil, e para o MERCOSUL - mas tem de ficar em discussão a atitude arrogante e agressiva dos Estados Unidos, em relação ao projeto continental de livre comércio. Isso tem de ser levado em conta, para entender a rejeição que vem suscitando projeto em si possível e que poderia ser útil para todos os países da região.

O paternalismo de irmão mais velho, não, obrigado, não precisamos dele. Por outro lado, cada vez mais, interessará ter acordos comerciais amplos e abrangentes, como temos o MERCOSUL, como temos o Acordo-quadro interregional de cooperação entre a União Européia e o MERCOSUL (Madri, 1995) e a complementação deste, que vem sendo negociada desde então, 
entre U.E. e MERCOSUL. Da mesma forma pode nos ser conveniente ter acordo comercial amplo, em escala continental. Contudo, depois de toda a poeira que se levantou contra, nesta altura, vai ser preciso esperar algum tempo até que se possa ter a tranquilidade para avaliar proposta como esta pelos seus aspectos técnicos. Neste momento, a discussão tornou-se passional.

A opinião pública nacional - que igualmente, pouco se importa com a maioria dos temas de politica externa - poderia ternder a ver como "rendição" ao peso da pressão norte-americana e "entreguismo" dos sacrossantos interesses nacionais, sem que ninguém defina quais sejam estes, em relação à aceitação ou rejeição da ALCA nesta fase. Ora, certamente não precisamos dessa "encrenca federal" neste momento. Temos de consolidar a estabilização e tentar fazer acontecer algum crescimento interno, temos de consolidar a reforma do estado, do descalabro da estratificação social e das distorções regionais, temos de consolidar o MERCOSUL, temos nossos parceiros comerciais e gama ampla de acordos e entendimentos em curso. Não precisamos ter essa agenda da ALCA forçada desse modo. Terá de passar algum tempo.

Na administração CLINTON se podia ver interesse efetivo em privilegiar as relações bilaterais com o Brasil. Menos se tem visto nesse sentido, na Administração BUSH Jr. Quem sabe o próximo presidente dos Estados Unidos pode ter um pouco mais de visão, para abordar e resolver de modo eficaz a questão do deficit estrutural de nossa balança comercial bilateral, pois do saldo negativo do ano passado, mais da metade foi resultado de desequilibrio entre compras e vendas brasileiras para os Estados Unidos. Isto sim, poderia ser útil: Como várias outras coisas que vem sendo evitadas: um acordo sobre investimentos, um acordo sobre bi-tributação e evasão fiscal. Sem essas matérias, ficará difícil para os governos tentar vender imagem de algum avanço significativo. Quanto às rivalidades de família, podemos passar sem estas! 
A construção de Área de Livre Comércio, em escala continental, poderá ser uma das grandes transformações no contexto das Américas, não somente em termos de comércio, por muitos anos. Mas esse Acordo terá de encontrar sua forma adequada e patamar de operacionalidade.

A formatação pretendida para o Acordo ALCA segue o mesmo padrão já negociado e adotado em relação ao NAFTA. A estrutura do documento e a construção do raciocínio e da estrutura legais são tipicamente do direito da "common law", com a multiplicação de casuismos e a perda da clareza dos conceitos mais relevantes, em meio ao oceano de pequenas exceções e nuances possiveis: ideais para nos fazerem perder o rumo do principal e acessório, às mentes legais criadas no modelo românico de formulação de princípios e regras gerais. O "pattern" é totalmente americano: quem não se habituar com este, pode ficar fora de contexto ${ }^{11}$.

Sem dúvida muitas dificuldades surgem em tais processos, pois além das condicionantes derivadas das flutuações de ordem política e da necessidade de se consolidarem estruturas institucionais estáveis e estados democráticos de direito, tanto internamente como supranacionalmente, caracterizando estrutura institucional ao mesmo tempo suficiente, resistente e flexivel, para fazer face aos entraves, compreensível e inevitavelmente colocados pelos Estados-membros, sem excluir a possibilidade de inserir ajustes necessários, durante a implementação do processo, destaca-se o papel a ser desempenhado pelo direito em processo de integração. A contraposição da importância do dado jurídico, no esforço de levar adiante a construção da integração, em relação ao pano de fundo de estruturais e crônicos problemas econômicos,

11 Nesse sentido, remeteria ao estudo desenvolvido em Renato FREIRE e Paulo CASELLA, Contratos financeiros internacionais: estudo de direito comparado anglo-norteamericano e brasileiro (S. Paulo, Ed. RT, 1994; 2a ed., no prelo, 2004). 
sociais e políticos, ante a evidência e premência destes, não precisa ser enfatizada.

A integração pressupõe a busca de equilíbrio entre os parceiros engajados na empreitada comum, independentemente das diferenças - sem isso, não há integração, mas 'neocolonialismo'. Os Estados Unidos, historicamente tinham se mostrado avessos a propostas e tentativas de integração regional, exceto se e na exata medida em que estivessem os Estados Unidos na dianteira. Ora, isso, justamente, não é integração, mas perpetuação de laços de dependência entre Estados (economica e politicamente) mais fortes e outros Estados (comparativamente como em termos absolutos) mais fracos.

Nisso se vê atitude contraditória dos norte-americanos em relação à proposta de zona de livre comércio para o conjunto das Américas: a ALCA, em si, poderia ser viável, poderia ser a extensão continental dos dois pólos iniciais de integração, onde a Associação de livre comércio da América do Norte (NAFTA), reunindo Canadá, Estados Unidos e México, de um lado, e o nosso MERCOSUL, reunindo Argentina, Brasil, Paraguai e Uruguai, e como associados, igualmente o Chile e a Bolívia, e ambos poderiam ser a transição lógica e natural rumo a espaço comercial sem barreiras no conjunto do Continente, da "Terra do Fogo ao Alasca".

Basta pensar que os três integrantes da NAFTA respondem por $80 \%$ do total do comércio das Américas, enquanto os quatro do MERCOSUL respondem por $8 \%$ desse total, para se ter a dimensão da relevância da concatenação de posições entre os dois blocos regionais, em relação ao comércio no Continente. Lógico e previsivel seria termos a progressão rumo à $A L C A$ consolidada a partir dos dois blocos existentes e operando, para construir sucessivamente laços efetivos de alcance continental. Isso sem esquecer o papel acessório que poderiam ainda desempenhar 
os outros blocos regionais, embora não estejam estes em grande forma, mas ilustrando a persistência de modelos e expectativas de integração, tal como a Comunidade Andina (CAN), o Mercado Comum do Caribe (CARICOM) e o Mercado Comum Centro Americano (MCCA).

Infelizmente não parece ser esta a tendência mais provável de evolução, na medida em que o peso e a falta de tato da política externa estadunidense tem se pautado pela pressão em lugar do diálogo. Ora, esse modelo de outros tempos, por sorte, há muito já ficou superado; não temos necessidade alguma de retomá-lo. Podemos perfeitamente viver sem ele! O quadro atual faz esperar poucos resultados concretos da atual gestão, restando esperar para ver os rumos que decorrerão das eleições presidenciais norteamericanas de 2004.

A proposta MERCOSUL em relação à agenda da ALCA afigura-se muito razoável, na medida em que pretende assegurar a uniformidade de abertura das economias nacionais, concatenando, simultaneamente, produtos manufaturados e tecnologia a regras semelhantes aos produtos agrícolas e agroindustriais, ao lado de normas setoriais que abrangeriam propriedade intelectual, serviços e investimentos, acesso a mercados (inclusive em relação a compras governamentais), direito da concorrência, normas "anti-dumping" bem como relativas a subsídios e o destaque para normas de solução de controvérsias. Todo relacionamento precisa de mecanismos institucionais de ajuste de diferenças. Poder manter a sintonia e superar diferenças é crucial para evitar desvios de rota que se tornem irremediáveis.

De que forma poderia ser estruturada a progressiva consolidação de área de livre comércio para o conjunto das Américas? Criando laços novos, a partir dos vínculos e compromissos já existentes, ampliando-os progressivamente, para abranger o conjunto dos 34 países do Continente - e afinal de 
contas, lembrando-nos igualmente de Cuba. Até quando vai durar o desterro da itha em seu próprio Continente? Em lugar de se dar conta de que os tempos de guerra fria já acabaram, vem sendo usada a interferência em relação ao governo de Havana como manobra diversionista, para despistar os estragos feitos por recentes invasões do Afganistão e Iraque, bem como ameaças em relação a Coréia do Norte e Síria.

É indispensável assegurar o equilíbrio da abertura dos mercados e economias nacionais. Não podemos repetir a abertura unilateral do início dos anos 90 , que teve efeitos internos benéficos, mas poderia ter sido mais vantajosamente negociada com os parceiros comerciais do Brasil. Não devemos nem podemos tampouco esquecer as enormes desigualdades entre os parceiros da empreitada, pois como dizia Ruy BARBOSA, o começo da iniquidade está em tratar desigualmente os iguais e igualmente os desiguais!

Com a mesma tranquilidade se pode afirmar:

- tecnicamente não existir incompatibilidade entre a continuidade do MERCOSUL, como acordo sub-regional de integração, tendente à configuração de mercado comum entre os países da região, inserido este grupo de países, já vinculados por acordo de integração mais abrangente em relação a outro acordo, este tendente a ser zona de livre comércio, em escala continental, na qual esteja inserido o MERCOSUL;

- politicamente será delicado ver se o MERCOSUL sobrevive a essa negociação da qual haverá de resultar a ALCA;

- a negociação da ALCA será extremamente pesada e difícil, ao mesmo tempo em que, 
- a negociação da ALCA é inevitável, para assegurar acesso do Brasil e do MERCOSUL a esse enorme mercado integrado no futuro;

- a ALCA pode viver sem o Brasil e sem o MERCOSUL;

- será que o Brasil e o MERCOSUL podem viver sem a ALCA ???

- o andamento e resultados da negociação de acordo comercial MERCOSUL - U.E. estarão estreitamente acompanhando a evolução da negociação da ALCA. 